\title{
La gratuidad progresiva en la educación superior. Una obligación de rango constitucional del Estado de Chile
}

\section{The progressive free-of-charge in the higher education. A constitutional obligation of the state of Chile}

Carola Canelo Figueroa ${ }^{1}$

\begin{abstract}
Resumen: se analiza el tema del derecho a la educación, focalizado en dos aspectos particulares: por una parte, se considera solo la educación superior (o universitaria); y, por otra, se plantea que el estado de Chile no ha cumplido con el deber de instalar progresivamente su gratuidad, como debería haber ocurrido, a la luz del Pacto Internacional de Derechos Económicos, Sociales y Culturales. Se analiza también la problemática asociada a la existencia de dos tipos de universidades: estatales y privadas. Finalmente, la propuesta es que Chile reemplace el sistema de financiamiento basado en los D.F.L. $\mathrm{N}^{\circ} 1$ y $\mathrm{N}^{\circ} 4$, de modo que en un plazo prudente (diez o veinte años) se llegue a una gratuidad total del sistema universitario.
\end{abstract}

Palabras clave: educación gratuita, derecho a la educación, financiamiento de la educación.

\begin{abstract}
On the one hand, it is only considered higher education (university). On the other hand, it suggests that Chilean state has not fulfilled its duty of set up progressively the free-on-charge education, as it should have happened in the light of the International Covenant on Economic, Social and Cultural Rights. It is also analysed the problems associated with the existence of two types of universities: public and private universities. Finally, it is developed a proposal which states that Chile replaces the financing system based on DFL $\mathrm{N}^{\circ} 1$ and $\mathrm{N}^{\circ} 4$, so that it reaches a free-on-charge higher education within a reasonable period (ten or twenty years).
\end{abstract}

Key words: free-on-charge education, right to education, education financing.

\section{Normativa constitucional}

La Constitución de la República en su artículo $19 \mathrm{~N}^{\circ} 10^{2}$ asegura y garantiza el Derecho a la educación. La Carta Fundamental prescribe lo siguiente:

Artículo 19.- La Constitución asegura a todas las personas:

$10^{\circ}$ - El Derecho a la educación.

\footnotetext{
${ }^{1}$ Licenciada en Ciencias Jurídicas y Sociales de la Facultad de Derecho de la Universidad de Chile. Master of Laws in International Legal Studies Program, en American University, Washington College of Law, Estados Unidos de América. Actualmente es académica adscrita a los Departamentos de Derecho Procesal y Derecho Internacional de la Facultad de Derecho de la Universidad de Chile y Coordinadora de académicos de la Facultad de Derecho de la Universidad de Chile. Correo electrónico: c.canelo@derecho.uchile.cl.

${ }^{2}$ CHILE. Constitución Política de la República de 1980.
} 
La educación tiene por objeto el pleno desarrollo de la persona en las distintas etapas de su vida.

Los padres tienen el Derecho preferente y el deber de educar a sus hijos. Corresponderá al Estado otorgar especial protección al ejercicio de este Derecho.

Para el Estado es obligatorio promover la educación parvularia y garantizar el acceso gratuito y el financiamiento fiscal al segundo nivel de transición, sin que éste constituya requisito para el ingreso a la educación básica.

La educación básica y la educación media son obligatorias, debiendo el Estado financiar un sistema gratuito con tal objeto, destinado a asegurar el acceso a ellas de toda la población. En el caso de la educación media este sistema, en conformidad a la ley, se extenderá hasta cumplir los 21 años de edad.

Corresponderá al Estado, asimismo, fomentar el desarrollo de la educación en todos sus niveles; estimular la investigación científica y tecnológica, la creación artística y la protección e incremento del patrimonio cultural de la Nación.

Es deber de la comunidad contribuir al desarrollo y perfeccionamiento de la educación.

De la norma constitucional transcrita es posible señalar lo siguiente:

1. No se define el derecho a la educación, sino que se hace una referencia a su objeto, cual es, el pleno desarrollo de la persona en las distintas etapas de su vida.

2. En relación al derecho a la educación, se incluye el derecho y deber preferente de los padres de educar a sus hijos.

3. Se establece la obligación del estado de promover la educación parvularia y garantizar el acceso gratuito y el financiamiento fiscal al segundo nivel de transición (kínder), sin que éste constituya requisito para el ingreso a la educación básica.

4. Se establece que la educación básica y media son obligatorias.

5. El estado debe financiar un sistema gratuito, destinado a asegurar el acceso a la Educación Básica y Educación Media de toda la población.

6. El Constituyente de 1980 no hace una referencia expresa al derecho a la Educación Superior, de lo cual se deduce que no la estima obligatoria ni de general acceso.

7. Tampoco señala el Constituyente de 1980 cuál es el rol del estado en relación al financiamiento de la Educación Superior. De lo cual se sigue que no pretendía ese Constituyente que el estado tuviera un rol en el financiamiento ni en la garantía de acceso a ese nivel educacional.

8. Se establece la obligación del estado de fomentar el desarrollo de la educación en todos sus niveles; estimular la investigación científica y tecnológica, la creación artística y la protección e incremento del patrimonio cultural de la Nación. Sólo en este párrafo el Constituyente de 1980 se refiere implícitamente a la Educación Superior, la que precisamente contiene la investigación científica tecnológica, la creación artística y la protección e incremento del patrimonio cultural de la Nación. Sin embargo, a ese respecto sólo genera una obligación de fomentarla, pero no genera una obligación de financiamiento por parte del estado, ni de garantizar el acceso general a ella. 


\begin{abstract}
A su vez, el artículo 19 n 11 de la Constitución ${ }^{3}$ garantiza la libertad de enseñanza:
\end{abstract}

Artículo 19.- La Constitución asegura a todas las personas:

$11^{\circ}$.- La libertad de enseñanza incluye el Derecho de abrir, organizar y mantener establecimientos educacionales.

La libertad de enseñanza no tiene otras limitaciones que las impuestas por la moral, las buenas costumbres, el orden público y la seguridad nacional.

La enseñanza reconocida oficialmente no podrá orientarse a propagar tendencia político partidista alguna.

Los padres tienen el Derecho de escoger el establecimiento de enseñanza para sus hijos.

Una ley orgánica constitucional establecerá los requisitos mínimos que deberán exigirse en cada uno de los niveles de la enseñanza básica y media y señalará las normas objetivas, de general aplicación, que permitan al Estado velar por su cumplimiento. Dicha ley, del mismo modo, establecerá los requisitos para el reconocimiento oficial de los establecimientos educacionales de todo nivel.

Conforme con este artículo, es posible señalar lo siguiente:

1. La Constitución de 1980 garantiza la libertad de enseñanza, entendida como el derecho de abrir, organizar y mantener establecimientos educacionales. El objetivo evidente de esta normativa es garantizar a los particulares la posibilidad de crear, establecer y operar establecimientos educacionales, de cualquier nivel.

2. La libertad de enseñanza se otorga de manera amplia como un derecho, reconociendo sólo como límite la moral, las buenas costumbres, el orden público y la seguridad nacional. En este sentido la norma constitucional es deficiente desde un punto de vista técnico, porque obviamente la actuación de los particulares en la creación y administración de establecimientos de enseñanza también está sujeto a la Constitución y a las leyes.

3. El Constituyente de 1980 rechaza el adoctrinamiento político partidista en la enseñanza, prohibiendo dicha actividad en el ámbito de la educación.

4. Se garantiza la libertad de los padres de elegir el establecimiento educacional donde sus hijos se educarán. Con ello se quita al Estado el rol en esta materia y se les asigna a los particulares la libertad de elección del establecimiento educacional.

5. Se le encomienda a una ley orgánica constitucional establecer los requisitos mínimos que deben cumplir los establecimientos de enseñanza básica y media y las normas para que el Estado pueda velar por su cumplimiento. No menciona el Constituyente igual encargo a la ley en materia de Educación Superior. Sólo incluye a la Educación Superior cuando ordena que esa misma ley establezca los requisitos

6. para el reconocimiento oficial de los establecimientos educacionales de todo nivel. Pero se limita a ello.

${ }^{3}$ Ibid. 
A su vez, el artículo 20 de la Constitución de $1980^{4}$, que consagra la acción constitucional de protección, sólo incluye como Derecho fundamental protegible, en materia de educación, a la libertad de enseñanza, pero no el Derecho a la educación.

En efecto, el artículo 20 prescribe:

Artículo 20.- El que por causa de actos u omisiones arbitrarios o ilegales sufra privación, perturbación o amenaza en el legítimo ejercicio de los Derechos y garantías establecidos en el artículo 19 , números $1^{\circ}, 2^{\circ}, 3^{\circ}$ inciso cuarto, $4^{\circ}, 5^{\circ}, 6^{\circ}, 9^{\circ}$ inciso final, $11^{\circ}, 12^{\circ}, 13^{\circ}, 15^{\circ}, 16^{\circ}$ en lo relativo a la libertad de trabajo y al Derecho a su libre elección y libre contratación, y a lo establecido en el inciso cuarto, $19^{\circ}, 21^{\circ}, 22^{\circ}, 23^{\circ}$, $24^{\circ}$, y $25^{\circ}$ podrá ocurrir por sí o por cualquiera a su nombre, a la Corte de Apelaciones respectiva, la que adoptará de inmediato las providencias que juzgue necesarias para restablecer el imperio del Derecho y asegurar la debida protección del afectado, sin perjuicio de los demás Derechos que pueda hacer valer ante la autoridad o los tribunales correspondientes.

Procederá, también, el recurso de protección en el caso del $\mathrm{N}^{\circ} 8^{\circ}$ del artículo 19 , cuando el Derecho a vivir en un medio ambiente libre de contaminación sea afectado por un acto u omisión ilegal imputable a una autoridad o persona determinada.

De todo lo antes expuesto es posible señalar lo siguiente:

1. Que el Constituyente de 1980 no dedicó normas expresas en materia de Educación Superior, no garantizó la libertad de cátedra, no reguló el concepto de Universidad ni tampoco impuso una obligación al Estado de financiar la Educación Superior, ni pública ni privada.

2. Lo anterior se funda en una concepción ideológica y política contraria a la intervención del Estado en materia educacional, y en particular en relación con la Educación Superior.

3. Además ello responde al contexto histórico de la época en que gobernaba un régimen militar, que accedió al poder mediante la fuerza, con el apoyo de algunos partidos políticos locales y de grupos extranjeros, en que no existía Congreso, y en que la creación de una nueva Constitución si bien fue sometida a plebiscito, no tuvo, a mi juicio, las garantías adecuadas para asegurar la participación de la Nación en su elaboración. Unido a lo anterior, existía un Poder Judicial que tampoco tenía garantías de independencia en su quehacer jurisdiccional, como incluso uno de los ex presidentes de la Excelentísima Corte Suprema lo ha reconocido públicamente.

4. El Constituyente de 1980 generó las bases de un nuevo sistema de Educación Superior, sobre la base de la garantía de la libertad de enseñanza, que sí garantiza, y que deja entregado básicamente a los particulares. Desatendiendo inclusive la educación pública superior, la que junto a la educación privada superior quedan sujetas a las mismas normas de rango legal como pasaremos a explicar.

${ }^{4}$ Ibíd. 


\section{Normativa legal}

Acorde con el texto de la Constitución de 1980, el Gobierno Militar estableció entonces un nuevo régimen legal de Educación Superior en el año 1981, mediante la dictación de los Decretos con Fuerza de Ley $\mathrm{N}^{\circ} 1$ y $\mathrm{N}^{\circ} 4$ de 1981. El D.F.L. $\mathrm{N}^{\circ} 1$ de 1981, fija normas sobre Universidades ${ }^{5}$ y el D.F.L. 4 de 1981, regula el financiamiento. Tal normativa sobre Educación Superior se encuentra vigente en Chile hasta el día de hoy.

El D.F.L. $\mathrm{N}^{\circ} 1$ de 1981 fue promulgado el 30 de Diciembre de 1980 y entró en vigencia, una vez que se publicó en el Diario Oficial con fecha 3 de enero de 1981. Este Decreto fue dictado por el Ministerio de Educación Pública, y fija normas sobre Universidades.

El artículo 1 del D.F.L $\mathrm{N}^{\circ} 1^{6}$ define lo que se entiende por universidad.

Artículo $1^{\circ}$ - La Universidad es una institución de Educación Superior, de investigación, raciocinio y cultura que, en el cumplimiento de sus funciones, debe atender adecuadamente los intereses y necesidades del país, al más alto nivel de excelencia.

Luego el artículo 2 del D.F.L. $\mathrm{N}^{\circ} 1^{7}$ señala las actividades que son especialmente responsabilidad de las universidades.

Artículo $2^{\circ}$ - Corresponde especialmente a las universidades:

a) Promover la investigación, creación, preservación y transmisión del saber universal y el cultivo de las artes y de las letras;

b) Contribuir al desarrollo espiritual y cultural del país, de acuerdo con los valores de su tradición histórica;

c) Formar graduados y profesionales idóneos, con la capacidad y conocimientos necesarios para el ejercicio de sus respectivas actividades;

d) Otorgar grados académicos y títulos profesionales reconocidos por el Estado, y

e) En general, realizar las funciones de docencia, investigación y extensión que son propias de la tarea universitaria.

Conforme a la normativa que establece el D.F.L. $\mathrm{N}^{\circ} 1$ la Universidad para ser tal debe dedicarse a la Educación Superior, al más alto nivel, a través de sus funciones propias de docencia, investigación y extensión, incluyendo dentro de sus funciones el otorgamiento de grados académicos y títulos profesionales reconocidos por el Estado.

En ese sentido, a mi juicio, el D.F.L. $\mathrm{N}^{\circ} 1$ brinda una definición y funciones de la universidad que son correctos, y que no deberían ser modificados. De existir instituciones que se denominen a sí mismas Universidad y no cumplan estas funciones que son de su esencia, a mi juicio, existe acción para exigir la revocación de su personalidad jurídica ante el Ministerio de Educación, conforme al procedimiento que establece el artículo 64 del

\footnotetext{
${ }_{6}^{5}$ CHILE. Ministerio de Educación Pública. D.F.L. 1 de 1981, fija normas sobre Universidades.

${ }^{6}$ Ibíd.

${ }^{7}$ Ibíd.
} 
D.F.L. $\mathrm{N}^{\circ} 2$ del Ministerio de Educación, publicado el 2 de julio de 2010, que fija el texto refundido, coordinado y sistematizado de la Ley $\mathrm{N}^{\circ} 20.370$, con las normas no derogadas del D.F.L. $\mathrm{N}^{\circ} 1$ del año 2005.

Sobre esta materia, me permito señalar que la iniciativa del Senado Universitario de la Universidad de Chile, contenida en el documento sobre "Nuevas bases para la institucionalidad de las Universidades", que propone distinguir entre "tipos" de universidades, algunas que denomina universidades docentes -que son aquellas que sólo imparten docencia y no cumplen los demás roles de una universidad- y otras universidades complejas -que son las que cumplen los roles o funciones universitarias de docencia, investigación y extensión- es absolutamente errada, ya que significa desconocer la esencia misma de la Universidad, como institución que debe cumplir con las funciones de investigación, docencia y extensión. Además, como propuesta incluso es regresiva en relación con la normativa actualmente vigente desde 1981 que exige a las universidades cumplir esas tres funciones. Adicionalmente, tal propuesta del Senado Universitario es contraria a la misión de la Universidad de Chile, que incluye la misión de velar por el desarrollo y la excelencia de la educación en el país.

Situación distinta a ello, es que existan instituciones que lleven el nombre de universidades y que sin embargo no cumplan las funciones que la ley les ha especialmente asignado. Esto es un tema de incumplimiento de la ley, lo que no debe llevar necesariamente a modificar la legislación para legitimar conductas ilegales que atentan contra el concepto mismo de Universidad. Por el contrario, atendida la situación actual en Chile de algunas universidades privadas creadas con posterioridad al año 1981 que no cumplen el rol universitario, el Ministerio de Educación debe hacer cumplir la normativa legal, y previo el debido procedimiento y, habiendo oído a la entidad afectada, cancelar la personalidad jurídica de aquellas universidades que no son tales, conforme al artículo 64 antes citado.

El mismo D.F.L. 1 da amplia libertad para crear universidades privadas, exigiendo únicamente que se constituyan como personas jurídicas de Derecho privado sin fines de lucro y que su acta constitutiva y estatutos consten en escritura pública o bien en instrumento privado reducido a escritura pública. Por el solo hecho de depositar los instrumentos constitutivos de una universidad privada, ésta adquiere personalidad jurídica por el solo ministerio de la ley. Luego el mismo D.F.L. establece que si existen reparos del Ministerio de Educación, la entidad deberá subsanarlos y de no hacerlo dentro de plazo, el Ministerio le cancelará la personalidad jurídica.

De esta normativa se sigue que el sentido de esta legislación es abrir ampliamente la posibilidad de crear universidades privadas sin mayores limitaciones, ni en su constitución ni menos en su funcionamiento.

En efecto, el artículo 15 del D.F.L. $\mathrm{N}^{\circ} 1$ de $1981^{8}$ prescribe:

Artículo $15^{\circ}$ - Podrán crearse universidades, las que deberán constituirse como personas jurídicas de Derecho privado sin fines de lucro.

${ }^{8}$ Ibid. 
Estas universidades se regirán por las disposiciones de la presente ley y de sus respectivos estatutos; supletoriamente, les serán aplicables las disposiciones del Título XXXIII del Libro I del Código Civil, en lo que no sean incompatibles con aquellas.

A su vez, los artículos $16,17,18$ y $19^{9}$ regulan las formalidades que deben cumplir en su constitución.

Artículo $16^{\circ}$ - Las universidades podrán constituirse por escritura pública o por instrumento privado reducido a escritura púbica, debiendo contener el acta de constitución y los estatutos por los cuales ha de regirse la entidad.

Artículo $17^{\circ}$ - Las universidades gozarán de personalidad jurídica por el solo hecho de depositar una copia del instrumento constitutivo a que se refiere el artículo anterior en un Registro que llevará al efecto el Ministerio de Educación.

Con todo, las universidades no podrán funcionar como tales sino una vez transcurrido el plazo a que se refiere el artículo siguiente, siempre que el Ministerio de Educación no hubiere objetado su constitución o sus estatutos y se hayan aprobado sus programas de estudios de conformidad a lo dispuesto en el artículo 24.

Artículo $18^{\circ}$ - El Ministerio de Educación no podrá negar el registro de una universidad y deberá autorizar una copia del instrumento constitutivo estampando en ella el número de registro correspondiente.

Sin embargo, dentro del plazo de 90 días contado desde la fecha del depósito, el Ministerio podrá objetar la constitución de la universidad si faltare cumplir algún requisito para constituirla, o si los estatutos no se ajustaren a lo prescrito por la ley.

Artículo $19^{\circ}$ - La universidad deberá subsanar los defectos de constitución o conformar sus estatutos a las observaciones formuladas por el Ministerio de Educación dentro del plazo de 60 días. Vencido este plazo sin que la Universidad haya procedido a subsanar los reparos, el Ministerio, mediante resolución, cancelará la personalidad jurídica a la Universidad, ordenando sea eliminada del Registro respectivo.

Por su parte, el D.F.L. $\mathrm{N}^{\circ} 4$ de 1981 fija normas sobre financiamiento de las Universidades $^{10}$. Se promulgó el 14 de enero de 1981 y se publicó en el Diario Oficial el 20 de Enero de 1981. Esta normativa es la que explica el por qué en Chile no hay gratuidad en la Educación Superior.

Este D.F.L. 4 de 1981 rige hasta el día de hoy. Conforme a este D.F.L. el Estado se obliga a financiar a las universidades existentes al 31 de diciembre de 1980 y de las instituciones que de ellas se derivaron mediante un aporte fiscal directo anual, cuyo cálculo regula esta normativa y que disminuye en el tiempo. En efecto, de un análisis de este D.F.L. se sigue que el sentido de la norma es que cada año el Estado le entregaría menos aporte directo a las universidades existentes al 31 de diciembre de 1980 y las que de ellas se derivaren.

También se deduce de esta normativa que el legislador de la época no distinguió entre universidades estatales, de naturaleza jurídica pública, de aquellas universidades privadas creadas con anterioridad al año 1981 ni las instituciones profesionales que se derivaren. Dándoles en consecuencia a todas ellas el mismo tratamiento.

\footnotetext{
${ }^{9}$ Ibíd.

${ }^{10}$ CHILE. Ministerio de Educación Pública. D.F.L. 4 de 1981, fija normas sobre financiamiento de las Universidades.
} 
En efecto, el artículo $1^{\circ}$ del D.F.L. $4^{11}$ prescribe:

Artículo primero: El estado contribuirá al financiamiento de las universidades existentes al 31 de diciembre de 1980 y de las instituciones que de ellas se derivaren, mediante aportes fiscales cuyo monto anual y distribución se determinarán conforme a las normas del presente título.

A su vez el artículo 2 del D.F.L. $N^{\circ} 4$ de $1981^{12}$ regula la forma en que dicho aporte fiscal directo se debe establecer. Fijando que se debe calcular año tras año y ser fijado en la Ley de Presupuesto del Sector Público.

Artículo 2. ${ }^{\circ}$ - El monto del aporte fiscal será fijado anualmente en la ley de Presupuestos del Sector Público.

La distribución del aporte entre las universidades e instituciones profesionales, a que se refiere el artículo $1 .^{\circ}$, se hará mediante decreto supremo expedido por intermedio del Ministerio de Educación Pública, el que deberá llevar, además, la firma del Ministro de Hacienda, y se calculará de acuerdo a las siguientes bases:

A) El 95\% del aporte correspondiente al año 1989, será entregado a las universidades e institutos profesionales en la misma proporción del aporte que recibieron en el año 1988.

El otro $5 \%$ de dicho aporte se distribuirá entre las universidades e institutos profesionales de acuerdo a un modelo de asignación de recursos.

B) En los años posteriores a 1989, las sumas que hayan correspondido a cada universidad e instituto profesional en el año inmediatamente anterior, como resultado de la aplicación de los dos porcentajes señalados en la letra precedente, serán la base para aplicar, respecto de cada una de esas entidades de Educación Superior, en el año respectivo, los porcentajes antes indicados.

Un reglamento, aprobado por decreto supremo del Ministerio de Educación Pública, que deberá llevar además la firma del Ministro de Hacienda, determinará el procedimiento de asignación del 5\% del aporte fiscal antes mencionado. Este proceso de asignación usará los siguientes coeficientes, como variables para determinar el nivel y progreso académicos de dichas instituciones:

a) alumnos de pregrado/número de carrera de pregrado.

b) alumnos de pregrado/jornadas académicas completas equivalente totales.

c) jornadas académicas completas equivalentes con grado académico de magíster y doctor/jornadas académicas completas equivalentes totales.

d) número de proyectos financiados por el Fondo Nacional de Ciencia y Tecnología y otros organismos/ jornadas académicas completas equivalentes totales.

e) número de publicaciones incorporadas a revistas científicas de reconocimiento internacional/jornadas académicas completas equivalentes totales.

De la letra b) antes transcrita se sigue que los montos asignados son siempre calculados sobre una base que es cada año menor, por ello, el sistema es regresivo en el tiempo.

\footnotetext{
${ }^{11}$ Íbíd.

${ }^{12}$ Íbíd.
} 
En consecuencia, el sistema de aporte fiscal directo ha significado para las Universidades tradicionales y específicamente para la Universidad de Chile, universidad de naturaleza jurídica estatal, que no más del $10 \%$ de su presupuesto sea financiado por el Estado, debiendo entonces la Universidad de Chile conseguir el $90 \%$ de su presupuesto para funcionar (pago de remuneraciones, y demás gastos propios de su actividad) mediante el acceso a otras fuentes de recursos, entre las que se destaca el cobro de aranceles, progresivamente onerosos a sus estudiantes. En otras palabras, la Educación Superior en Chile no es gratuita, ni siquiera la estatal, ya que las universidades del Estado financian la mayor parte de su presupuesto mediante el cobro de aranceles. Esto explica por qué las universidades estatales cobran aranceles incluso superiores al arancel de referencia que elabora el Ministerio de Educación para fines de becas y otros conceptos.

Adicionalmente, el D.F.L. $N^{\circ} 4$ establece que un 5\% del aporte fiscal directo se entregará sobre la base de una serie de cálculos que se basan en la idea de nivel y progreso académico. Sin embargo, estos conceptos son abordados de una manera meramente cuantitativa asumiendo ciertas premisas que no necesariamente son demostrativas de un mayor nivel académico de una institución. Así por ejemplo, se consideran como elementos de importancia para la asignación de esos recursos, el número de alumnos en relación con el número de carreras, o bien, el número de proyectos financiados por el Fondo Nacional de Ciencia y Tecnología en relación con el número de jornadas académicas completas equivalentes totales.

Estos tipos de conceptos desconocen que existen ciertas carreras universitarias, como la de Derecho, por ejemplo, en que parte importante de sus académicos ejercen activamente la profesión, incluso en roles de relevancia pública, como jueces, fiscales, defensores, y que, en consecuencia, tienen límites de jornada para realizar actividad académica en la universidad. Desconoce, entonces, estos conceptos el rol que debe cumplir la universidad en la relación de sus estudiantes con la realidad profesional y con la realidad del país, la cual los maestros proyectan en sus estudiantes en la medida que aquellos tienen reconocida experiencia profesional y académica a nivel nacional e internacional. Estos tipos de cálculos que contiene la legislación tienen sentido en una concepción de la universidad como centro de enseñanza alejado de la realidad nacional y en que se persigue que los académicos sólo giren en torno al mundo académico de tipo teórico sin mayor relación con los problemas y necesidades del país.

Adicionalmente, este D.F.L. $\mathrm{N}^{\circ} 4$ crea el aporte fiscal indirecto que el Estado entrega a todas las universidades, sean públicas o privadas, creadas antes y después de 1981, y a los Institutos Profesionales y Centros de Formación Técnica, que reciban a los estudiantes de mejores puntajes en la PSU (Prueba de Selección Universitaria), antes Prueba de Aptitud Académica (PAA).

En efecto, el artículo 3 del D.F.L. $\mathrm{N}^{\circ} 4^{13}$ prescribe:

Artículo $3 .^{\circ}$ - Sin perjuicio del aporte referido en el artículo anterior, el Estado otorgará a todas las universidades, institutos profesionales y centros de formación técnica, reconocidos por aquel como instituciones de Educación Superior, anualmente un aporte fiscal indirecto, el que será distribuido de la siguiente forma:

${ }^{13}$ Ibíd. 
1. El Ministerio de Educación Pública elaborará un listado con los primeros 27.500 puntajes de los alumnos matriculados en el primer año de estudios, en el año inmediatamente anterior, en las instituciones de Educación Superior, ordenado de menor a mayor de acuerdo con los puntajes obtenidos en la Prueba de Aptitud Académica, partes verbal y matemática.

2. Dicho listado será dividido en cinco tramos de similar número de alumnos cada uno, con factores de ponderación 1, 3, 6, 9 y 12, respectivamente, para los tramos 1, 2, 3, 4 y 5 .

El tramo 1 corresponderá a los puntajes más bajos y el tramo 5 a los puntajes más altos.

Los alumnos que hayan obtenido igual puntaje en la Prueba de Aptitud Académica deberán figurar en un mismo tramo. Al efecto se aumentará el número de alumnos del tramo en que figure la mayor cantidad del mismo puntaje y se disminuirá en la misma cantidad el otro tramo.

3. El número de alumnos de cada tramo será multiplicado por los factores correspondientes, establecidos en el punto anterior.

4. El monto base de recursos que se entregarán por cada alumno, se determinará dividiendo la cantidad asignada para estos efectos en la ley de Presupuestos por la suma del producto de las multiplicaciones obtenidas en el punto anterior.

5. A dicho monto base se le aplicará el factor de ponderación que corresponda a cada alumno, según sea el tramo en que se ubique de acuerdo con su puntaje en la Prueba de Aptitud Académica, determinándose de esta manera el monto de recursos que se asignarán por cada alumno ubicado en los tramos 1 al 5 .

6. Para determinar el monto de aporte fiscal que por este concepto corresponde a cada institución de Educación Superior, se procederá de la siguiente forma:

a) Los alumnos matriculados en el año inmediatamente anterior en el primer año de estudios de cada institución de Educación Superior, se ubicarán en el tramo que les corresponda, de acuerdo con el puntaje obtenido en la Prueba de Aptitud Académica.

b) El número de alumnos que de esta forma resulte en cada tramo, se multiplicará por el monto de recursos determinado por cada tramo en el punto 5 .

c) La suma de los valores así obtenidos determinará el monto total para el año respectivo, que corresponderá a cada institución de Educación Superior.

7. En el listado de alumnos señalado en el número 1, no se considerarán los alumnos que ingresen por segunda vez a una misma institución de Educación Superior. Tampoco se considerarán los alumnos que ingresen por tercera vez, a una misma o a otra institución de Educación Superior.

8. El monto determinado para cada institución, será sancionado por decreto supremo expedido por intermedio del Ministerio de Educación Pública, el que deberá ser suscrito también por el Ministro de Hacienda, y se entregará mensualmente a cada una de ellas un duodécimo de dicha cantidad.

De esta norma se sigue que las universidades privadas, especialmente aquellas creadas con posterioridad al año 1981 que carecen de tradición y de prestigio en el ámbito local e internacional, prácticamente deban "perseguir" a aquellos alumnos que obtienen altos puntajes en la PSU, para ofrecerles todo tipo de becas y beneficios (incluso 
computadores, autos y otros bienes de consumo) con el fin de obtener el aporte fiscal indirecto. Así, un estudiante de clase media, según las mediciones del gobierno de turno, obtiene un alto puntaje, y quisiera estudiar, por ejemplo, la carrera de Derecho en la Universidad de Chile, no podrá acceder a becas debido a que su condición socioeconómica no es de pobreza. Por lo tanto, frente a esa situación, este estudiante tiene como alternativa, o estudiar en la Universidad de Chile, con crédito bancario o bien ingresar a una universidad privada con beca completa. El sistema del AFI genera este tipo de efectos perversos que deja entregado a la lucha del mercado una decisión tan trascendental como la vida universitaria y la Educación Superior en nuestro país.

Las cifras demuestran que cada año, las universidades privadas creadas con posterioridad al año 1981 que son una de las principales entidades que realizan marketing y publicidad en Chile (en un nivel similar al de las empresas del retail como La Polar) tienen un mayor acceso al Aporte Fiscal Indirecto, forma de financiamiento que realiza el Estado a los particulares.

Así, por ejemplo, la carta del Honorable Diputado Alberto Robles en que solicitó, con el respaldo de 59 diputados, la creación de una Comisión Especial Investigadora sobre el funcionamiento de la Educación Superior, señala en relación al gasto en publicidad de las universidad privadas post 1981: "Anualmente gastan cerca de 60 millones de dólares sólo en publicidad, ubicándose después de las grandes tiendas y la telefonía celular."

A lo que se debe agregar el financiamiento que en el fondo le proporciona el Estado a las universidades privadas, en cuanto personas jurídicas sin fines de lucro que gozan de los beneficios tributarios respectivos. Pudiendo, por ejemplo, recibir donaciones, las que gozan de un especial tratamiento tributario.

\section{Pacto internacional de derechos económicos, sociales y culturales}

El año 1989, el general Augusto Pinochet Ugarte promulgó mediante el Decreto $\mathrm{N}^{\circ}$ 326, de fecha 28 de abril de 1989, el Pacto Internacional de Derechos Económicos, Sociales y Culturales $^{14}$, el que fue publicado como Ley de la República el 27 de mayo de 1989 en el Diario Oficial. Este tratado internacional fue suscrito por Chile en 1969, ratificado en la década de 1970, siendo promulgado y publicado en 1989.

Este Tratado internacional regula de manera más pormenorizada el Derecho a la educación, complementando de esta forma la normativa de la Constitución de 1980.

En efecto, el artículo 13 del Pacto ${ }^{15}$ señala:

Artículo 13:

1. Los Estados Partes en el presente Pacto reconocen el Derecho de toda persona a la educación. Convienen en que la educación debe orientarse hacia el pleno desarrollo de

${ }^{14}$ CHILE. Ministerio de Relaciones Exteriores. Decreto $\mathrm{N}^{\circ} 326$, promulga el Pacto Internacional de Derechos Económicos, sociales y culturales, adoptado por la Asamblea General de la Organización de las Naciones Unidas el 19 de diciembre de 1966, suscrito por Chile el 16 de septiembre de 1969.

${ }^{15}$ Ibíd. 
la personalidad humana y del sentido de su dignidad, y debe fortalecer el respeto por los Derechos humanos y las libertades fundamentales. Convienen asimismo en que la educación debe capacitar a todas las personas para participar efectivamente en una sociedad libre, favorecer la comprensión, la tolerancia y la amistad entre todas las naciones y entre todos los grupos raciales, étnicos o religiosos, y promover las actividades de las Naciones Unidas en pro del mantenimiento de la paz.

2. Los Estados Partes en el presente Pacto reconocen que, con objeto de lograr el pleno ejercicio de este Derecho:

a) La enseñanza primaria debe ser obligatoria y asequible a todos gratuitamente;

b) La enseñanza secundaria, en sus diferentes formas, incluso la enseñanza secundaria técnica y profesional, debe ser generalizada y hacerse accesible a todos, por cuantos medios sean apropiados $\mathrm{y}$, en particular, por la implantación progresiva de la enseñanza gratuita;

c) La enseñanza superior debe hacerse igualmente accesible a todos, sobre la base de la capacidad de cada uno, por cuantos medios sean apropiados, y en particular, por la implantación progresiva de la enseñanza gratuita;

d) Debe fomentarse o intensificarse, en la medida de lo posible, la educación fundamental para aquellas personas que no hayan recibido o terminado el ciclo completo de instrucción primaria;

e) Se debe proseguir activamente el desarrollo del sistema escolar en todos los ciclos de la enseñanza, implantar un sistema adecuado de becas, y mejorar continuamente las condiciones materiales del cuerpo docente.

3. Los Estados Partes en el presente Pacto se comprometen a respetar la libertad de los padres y, en su caso de los tutores legales, de escoger para sus hijos o pupilos escuelas distintas de las creadas por las autoridades públicas, siempre que aquéllas satisfagan las normas mínimas que el Estado prescriba o apruebe en materia de enseñanza; y de hacer que sus hijos o pupilos reciban la educación religiosa o moral que esté de acuerdo con sus propias convicciones.

4. Nada de lo dispuesto en este artículo se interpretará como una restricción de la libertad de los particulares y entidades para establecer y dirigir instituciones de enseñanza, a condición de que se respeten los principios enunciados en el párrafo $1 \mathrm{y}$ de que la educación en esas instituciones se ajuste a las normas mínimas que prescriba el Estado.

A su vez, este Pacto contiene normas transitorias para aquellos Estados que a la fecha de su entrada en vigencia no haya cumplido con la obligatoriedad y gratuidad de la enseñanza primaria, dándole un plazo de dos años para adoptar un plan que fije años y forma de implementarla ${ }^{16}$.

Artículo 14:

Todo Estado Parte en el presente Pacto que, en el momento de hacerse parte en él, aún no haya podido instituir en su territorio metropolitano o en otros territorios sometidos a su jurisdicción la obligatoriedad y la gratuidad de la enseñanza primaria, se compromete a elaborar y adoptar, dentro de un plazo de dos años, un plan detallado de

${ }^{16}$ Ibíd. 
acción para la aplicación progresiva, dentro de un número razonable de años fijado en el plan, del principio de la enseñanza obligatoria y gratuita para todos.

A su vez, el artículo $15^{17}$ prescribe:

Artículo 15:

1. Los Estados Partes en el presente Pacto reconocen el Derecho de toda persona a:

a) Participar en la vida cultural;

b) Gozar de los beneficios del progreso científico y de sus aplicaciones;

c) Beneficiarse de la protección de los intereses morales y materiales que le correspondan por razón de las producciones científicas, literarias o artísticas de que sea autora.

2. Entre las medidas que los Estados Partes en el presente Pacto deberán adoptar para asegurar el pleno ejercicio de este Derecho, figurarán las necesarias para la conservación, el desarrollo y la difusión de la ciencia y de la cultura.

3. Los Estados Partes en el presente Pacto se comprometen a respetar la indispensable libertad para la investigación científica y para la actividad creadora.

4. Los Estados Partes en el presente Pacto reconocen los beneficios que derivan del fomento y desarrollo de la cooperación y de las relaciones internacionales en cuestiones científicas y culturales.

Este tratado internacional en cuanto regula el derecho a la educación, que es un derecho esencial que emana de la persona humana, tiene rango constitucional, por aplicación del artículo $5^{\circ}$ de la Carta Fundamental.

En el mismo sentido deben aplicarse la Declaración Universal de los Derechos Humanos (artículo 26), la Convención Interamericana de Derechos Humanos y demás tratados internacionales sobre Derechos esenciales ratificados por Chile y que se encuentren vigentes.

En efecto, el artículo 5 de la Constitución ${ }^{18}$, según la reforma de 1989, prescribe:

Artículo $5^{\circ}$.- La soberanía reside esencialmente en la Nación. Su ejercicio se realiza por el pueblo a través del plebiscito y de elecciones periódicas y, también, por las autoridades que esta Constitución establece. Ningún sector del pueblo ni individuo alguno puede atribuirse su ejercicio.

El ejercicio de la soberanía reconoce como limitación el respeto a los Derechos esenciales que emanan de la naturaleza humana. Es deber de los órganos del Estado respetar y promover tales Derechos, garantizados por esta Constitución, así como por los tratados internacionales ratificados por Chile y que se encuentren vigentes.

De esta forma, el Estado de Chile desde el año 1989 ha estado obligado constitucionalmente a implementar progresivamente la gratuidad en la Educación Superior. Obligación que el Estado de Chile ha incumplido reiteradamente hasta la fecha, ya que los aranceles universitarios son cada vez más onerosos y el Estado lejos de implementar gratuidad progresiva ha implementado mecanismos, tales como el crédito con aval del

\footnotetext{
${ }^{17}$ Ibíd.

${ }^{18}$ Ibid.
} 
Estado, que han significado para los estudiantes y sus familias, financiar altos niveles de aranceles y de intereses bancarios asociados. Lo que ha producido un alto endeudamiento en la población.

El Estado ni siquiera ha cumplido esta obligación respecto de la educación pública en que los aranceles son tan altos e, incluso, más altos, según carrera o institución, que en las mismas universidades privadas.

El Estado, en cambio, ha seguido actuando conforme al D.F.L. $\mathrm{N}^{\circ} 4$ de 1981 normativa que es inconstitucional, a mi juicio, ya que a su respecto prevalece el Pacto de 1989, que es de rango constitucional. A mi juicio, el sentido de la reforma constitucional de 1989 fue darle aplicación o exigibilidad inmediata a los tratados que regulan Derechos esenciales, en términos que no requieren de una ley de implementación para regir ni menos para tener rango constitucional. De lo contrario, no habría tenido sentido la reforma constitucional de 1989 y la referencia expresa que hace el Constituyente en esa reforma a los tratados que regulan Derechos esenciales, colocándolos al mismo nivel que la normativa constitucional que regula los Derechos Humanos.

Este incumplimiento, sin perjuicio que puede generar responsabilidad del Estado de Chile a nivel internacional en el ámbito de la Organización de las Naciones Unidas, en cuyo ámbito se suscribió este tratado, genera responsabilidad del Estado para con sus habitantes, en cuanto el Pacto integra con rango constitucional el ordenamiento jurídico chileno vigente.

Este incumplimiento reiterado genera responsabilidades, las que pueden hacerse efectivas ante los tribunales de justicia, mediante el debido proceso legal que corresponda. Vía que, a mi juicio, corresponde ejercer atendida la omisión por parte del Poder Ejecutivo y Legislativo de nuestro país de dar estricto cumplimiento a la normativa.

En suma, lo que se discute hoy a nivel político y social en cuanto a becas y beneficios a los estudiantes más desposeídos y mediante una Ley Anual de Presupuesto Público no resuelve el problema planteado ni el incumplimiento del Estado en esta materia.

En efecto, las becas y beneficios sólo son asignadas a quienes son los más pobres, requisito que no se considera por el Pacto. Ya que, conforme al mismo, lo relevante en materia de enseñanza superior es la capacidad intelectual de cada uno, y todos, quienes tienen capacidad, independientemente de su posición económica o social, tienen derecho a una progresiva gratuidad. La normativa no discrimina entre ricos y pobres, ni quienes son de clase media.

De hecho, durante los gobiernos de la Concertación tampoco se intentó modificar sustancialmente el sistema de 1981, desconociendo el Pacto Internacional citado y sólo se dictaron leyes a partir del año 1998 que introdujeron incrementos adicionales al financiamiento, como lo propone del mismo modo hoy el Gobierno. Así se puede observar en las "NOTAS" contenidas en el D.F.L. $\mathrm{N}^{\circ} 4$ las diversas leyes que tuvieron por fin incrementar el presupuesto fiscal a las universidades ${ }^{19}$.

\footnotetext{
19 “Nota 1: El artículo 18 de la Ley 19595, publicada el 02.12.1998, dispuso incrementar en \$1.536.000 miles el aporte establecido por el presente artículo para 1998. La distribución de este incremento entre las Instituciones de Educación Superior se hará en la misma proporción que corresponda al aporte inicial correspondiente al año 1998.".
} 


\section{Propuestas}

A mi juicio es imperioso que se dicte, previa proposición del Ejecutivo y debate en el Congreso, una nueva Ley de Educación Superior para Chile, que reemplace el sistema de financiamiento de los D.F.L. $\mathrm{N}^{\circ} 1$ y $\mathrm{N}^{\circ} 4$ antes analizados, y que mantenga del D.F.L. $\mathrm{N}^{\circ} 1$ el sistema mixto de enseñanza superior (esto es universidades públicas y privadas), las definiciones de universidad y su obligación de no perseguir fines de lucro, y derogar el D.F.L. $\mathrm{N}^{\circ} 4$ a fin de establecer un aumento progresivo del financiamiento del Estado a las universidades públicas, con la obligación consiguiente de esas universidades de rebajar los aranceles a sus estudiantes, hasta una progresiva gratuidad. Esta ley puede establecer un plazo de 10 a 20 años para lograr el $100 \%$ del financiamiento estatal y por consiguiente el $100 \%$ de gratuidad para sus estudiantes.

Del mismo modo, propongo que se regule especialmente la situación de las universidades privadas existentes al año 1981 y de las instituciones que derivaron de las universidades estatales, en términos de que el Estado repare el abandono en que quedaron esas instituciones durante el gobierno militar y posteriores gobiernos de la Concertación, y se fijen las bases para que éstas logren autofinanciarse en el tiempo. Lo anterior sobre la base que las instituciones privadas no deberían ser financiadas por el Estado, salvo que otorguen servicios de Educación Superior de manera gratuita a sus estudiantes.

Propongo que se derogue el aporte fiscal indirecto, atendido que el Estado no debe financiar a las universidades privadas, ya que éstas por su naturaleza de personas jurídicas sin fines de lucro ya reciben beneficios tributarios del Estado.

De esta forma se estará, por una parte, respetando la libertad de enseñanza en cuanto existan universidades públicas y privadas, y, al mismo tiempo, se estará respetando el deber del Estado de implementar progresivamente la gratuidad en la Educación Superior. Lo que redundará en un sistema de educación pública superior con mayor financiamiento y con los necesarios aportes para desarrollar de manera correcta su función social de servir al país.

\footnotetext{
“Nota 2: El artículo 18 de la Ley 19703, publicada el 04.12.2000, dispuso incrementar en \$1.680.273 miles el aporte establecido por el presente artículo para el año 2000."

"Nota 3: El artículo 18 de la Ley 19775, publicada el 30.11.2001, dispuso incrementar en \$ 1.755.885 miles, el aporte establecido por el presente artículo para el año 2001."

"Nota 4: El Art. 18 de la Ley 19843, publicada el 05.12.2002, dispuso incrementar en \$ 1.808 .562 miles, el aporte establecido por el presente artículo para el año 2002."

"Nota 5: El Art. 18 de la Ley 19917, publicada el 04.12.2003, dispuso incrementar en \$1.848.350 miles, el aporte establecido por el presente artículo para el año 2003."

"Nota 6: El artículo 18 de la Ley 19985, publicada el 02.12.2004, dispuso incrementar en \$1.913.042 miles, el aporte que establece el presente artículo, para el año 2004. Dicho aporte incluye los recursos para otorgar los beneficios a que se refieren los artículos 14 y 15, al personal no académico de las universidades estatales.".

"Nota 7: El artículo 17 de la Ley 20079, publicada el 30.11.2005, incrementó en \$ 2.327.014 miles, el aporte que establece este artículo para el año 2005. Dicho aporte incluye los recursos para otorgar los beneficios a que se refieren los artículos 13 y 14, al personal académico y no académico de las universidades estatales.".

"Nota 8: El artículo 17 de la Ley 20313, publicada el 04.12.2008, incrementó en \$ 2.878 .625 miles, el aporte que establece este artículo para el año 2008. Dicho aporte incluye los recursos para otorgar los beneficios a que se refieren los artículos 13 y 14, al personal académico y no académico de las universidades estatales.”.
} 
Esto supone resguardar en la ley las fuentes de recursos necesarias, que quizás consistirán en alguna parte de la recaudación tributaria existente que se redestine de manera permanente a la Educación Superior pública o bien la dictación de nueva normativa tributaria que resuelva el tema. Cualquiera sea la forma, serán todos los contribuyentes los que financiarán este cambio, debiendo por cierto aportar quienes tienen más recursos, conforme a una política tributaria progresiva como corresponde.

Lo anterior, se entiende sin perjuicio del legítimo derecho que tienen los estudiantes, especialmente de universidades estatales para ejercer las acciones judiciales que procedieren contra el Estado por el incumplimiento de su obligación constitucional de implementar la gratuidad progresiva en la Educación Superior.

Esto último se refuerza si consideramos que antes del régimen militar la Educación Superior pública era prácticamente gratuita y una responsabilidad primordial del Estado.

En efecto, los artículos 153 y 154 de la Constitución Política de $1833^{20}$ prescribían:

Art. 153. La educación pública es una atención preferente del Gobierno. El Congreso formará un plan general de educación nacional; i el Ministro del Despacho respectivo le dará cuenta anualmente del estado de ella en toda la República.

Art. 154. Habrá una superintendencia de educación pública, a cuyo cargo estará la inspección de la enseñanza nacional, i su dirección bajo la autoridad del Gobierno.

A su vez, la Constitución de $1925^{21}$, con la reforma de 1970, prescribía en su artículo 10.

Art. 10. Asimismo, la Constitución asegura a todos los habitantes de la República:

7. La libertad de enseñanza.

La educación básica es obligatoria.

La educación es una función primordial del Estado, que se cumple a través de un sistema nacional del cual forman parte las instituciones oficiales de enseñanza y las privadas que colaboren en su realización, ajustándose a los planes y programas establecidos por las autoridades educacionales.

La organización administrativa y la designación del personal de las instituciones privadas de enseñanza serán determinadas por los particulares que las establezcan, con sujeción a las normas legales.

Sólo la educación privada gratuita y que no persiga fines de lucro recibirá del Estado una contribución económica que garantice su financiamiento, de acuerdo a las normas que establezca la ley.

La educación que se imparta a través del sistema nacional será democrática, y pluralista y no tendrá orientación partidaria oficial. Su modificación se realizará también en forma democrática, previa libre discusión en los organismos competentes de composición pluralista.

Habrá una Superintendencia de Educación Pública, bajo la autoridad del Gobierno, cuyo Consejo estará integrado por representantes de todos los sectores vinculados al

\footnotetext{
${ }^{20}$ CHILE. Constitución Política de la República de 1833.
}

${ }^{21}$ CHILE. Constitución Política de la República de 1925. 
sistema nacional de educación. La representación de estos sectores deberá ser generada democráticamente.

La Superintendencia de Educación tendrá a su cargo la inspección de la enseñanza nacional.

Los organismos técnicos competentes harán la selección de los textos de estudio sobre la base de concursos públicos a los cuales tendrán acceso todos los educadores idóneos, cualquiera que sea su ideología.

Habrá facilidades equitativas para editar y difundir esos textos escolares, y los establecimientos educacionales tendrán libertad para elegir los que prefieran.

Las Universidades estatales y las particulares reconocidas por el Estado son personas jurídicas dotadas de autonomía académica, administrativa y económica

Corresponde al Estado proveer a su adecuado financiamiento para que puedan cumplir sus funciones plenamente, de acuerdo a los requerimientos educacionales, científicos y culturales del país.

El acceso a las Universidades dependerá exclusivamente de la idoneidad de los postulantes, quienes deberán ser egresados de la enseñanza media o tener estudios equivalentes, que les permitan cumplir las exigencias objetivas de tipo académico. El ingreso y promoción de profesores e investigadores a la carrera académica se hará tomando en cuenta su capacidad y aptitudes

El personal académico es libre para desarrollar las materias conforme a sus ideas, dentro del deber de ofrecer a sus alumnos la información necesaria sobre las doctrinas y principios diversos y discrepantes.

Los estudiantes universitarios tienen Derecho a expresar sus propias ideas y a escoger, en cuanto sea posible, la enseñanza y tuición de los profesores que prefieran;

17. El Derecho a participar activamente en la vida social, cultural, cívica, política y económica con el objeto de lograr el pleno desarrollo de la persona humana y su incorporación efectiva a la comunidad nacional. El Estado deberá remover los obstáculos que limiten, en el hecho, la libertad e igualdad de las personas y grupos, y garantizará y promoverá su acceso a todos los niveles de la educación y la cultura y a los servicios necesarios para conseguir esos objetivos, a través de los sistemas e instituciones que señale la ley.

Las Juntas de Vecinos, Centros de Madres, Sindicatos, Cooperativas y demás organizaciones sociales mediante las cuales el pueblo participa en la solución de sus problemas y colabora en la gestión de los servicios del Estado y de las Municipalidades, serán personas jurídicas dotadas de independencia y libertad para el desempeño de las funciones que por la ley les correspondan y para generar democráticamente sus organismos directivos y representantes, a través del voto libre y secreto de todos sus miembros.

En ningún caso esas instituciones podrán arrogarse el nombre o representación del pueblo, ni intentar ejercer poderes propios de las autoridades del Estado.

Del mismo modo, en el Derecho Comparado es posible advertir que en los países latinoamericanos, la educación pública es gratuita, incluida la Educación Superior. 
Así en Argentina, el artículo $75 .^{\circ}$ número 19 de la Constitución Nacional ${ }^{22}$ establece la obligación del Congreso de garantizar los principios de gratuidad y equidad de la Educación Pública Estatal y la autonomía y autarquía de las universidades nacionales.

En Perú, la Constitución establece la gratuidad de la educación pública, inclusive la Educación Superior, para quienes tienen los méritos académicos para permanecer en ella y que no tengan suficientes recursos económicos para solventarla. El artículo 17 prescribe:

Artículo 17. La educación inicial, primaria y secundaria son obligatorias. En las instituciones del Estado, la educación es gratuita. En las universidades públicas el Estado garantiza el Derecho a educarse gratuitamente a los alumnos que mantengan un rendimiento satisfactorio y no cuenten con los recursos económicos necesarios para cubrir los costos de educación.

Conforme a la Constitución de los Estados Mexicanos toda la educación que el Estado imparta es gratuita.

La Constitución de la República Oriental del Uruguay garantiza la libertad de enseñanza y declara de utilidad social la gratuidad de la enseñanza pública superior, en los artículos 68 a 71 .

Del mismo modo, la Constitución Española ${ }^{23}$ en su artículo 27 reconoce y regula el derecho a la educación.

Artículo 27.

1. Todos tienen el Derecho a la educación. Se reconoce la libertad de enseñanza.

2. La educación tendrá por objeto el pleno desarrollo de la personalidad humana en el respeto a los principios democráticos de convivencia y a los Derechos y libertades fundamentales.

3. Los poderes públicos garantizan el Derecho que asiste a los padres para que sus hijos reciban la formación religiosa y moral que esté de acuerdo con sus propias convicciones.

4. La enseñanza básica es obligatoria y gratuita.

5. Los poderes públicos garantizan el Derecho de todos a la educación, mediante una programación general de la enseñanza, con participación efectiva de todos los sectores afectados y la creación de centros docentes.

6. Se reconoce a las personas físicas y jurídicas la libertad de creación de centros

7. Los profesores, los padres y, en su caso, los alumnos intervendrán en el control y gestión de todos los centros sostenidos por la Administración con fondos públicos, en los términos que la ley establezca.

8. Los poderes públicos inspeccionarán y homologarán el sistema educativo para garantizar el cumplimiento de las leyes.

9. Los poderes públicos ayudarán a los centros docentes que reúnan los requisitos que la ley establezca.

\footnotetext{
${ }^{22}$ ARGENTINA. Constitución Política de la Nación Argentina de 1994.

${ }^{23}$ ESPAÑA. Constitución española de 1978.
} 
10. Se reconoce la autonomía de las Universidades, en los términos que la ley establezca.

En consecuencia, la situación en Chile es bastante particular y alejada de la realidad de países que comparten la misma cultura jurídica, lo que demuestra que existe una vulnerabilidad en nuestro sistema atendida la falta de cumplimiento por parte del Estado de normativa que se encuentra vigente y que la sociedad demanda esté en pleno vigor.

El mayor financiamiento del Estado a sus universidades, debe quedar obviamente sujeto al principio de probidad administrativa y a la transparencia que exige el artículo 8 de la Carta Fundamental y la Ley de Acceso a la Información Pública que, a mi juicio, rige a las Universidades Estatales, debido a su naturaleza jurídica de instituciones del Estado.

\section{Referencias bibliográficas}

ARGENTINA. Constitución Política de la Nación Argentina de 1994.

ESPAÑA. Constitución española de 1978.

CHILE. Constitución Política de la República de 1833.

CHILE. Ministerio de Relaciones Exteriores. Decreto $\mathrm{N}^{\circ} 326$, promulga el Pacto Internacional de Derechos Económicos, sociales y culturales, adoptado por la Asamblea General de la Organización de las Naciones Unidas el 19 de diciembre de 1966, suscrito por Chile el 16 de septiembre de 1969.

CHILE. Constitución Política de la República de 1925.

CHILE. Constitución Política de la República de 1980.

CHILE. Ministerio de Educación Pública. D.F.L. 1 de 1981, fija normas sobre Universidades.

CHILE. Ministerio de Educación Pública. D.F.L. 4 de 1981, fija normas sobre financiamiento de las Universidades. 